\title{
Evidências de Validade do Inventário do Livre- Arbítrio (ILA) para a População Brasileira
}

\author{
Thiago Rafael Santin, Felipe Vilanova ${ }^{1}$ \\ Universidade Federal do Rio Grande do Sul, Porto Alegre-RS, Brasil \\ Ângelo Brandelli Costa \\ Pontifícia Universidade Católica do Rio Grande do Sul, Porto Alegre-RS, Brasil \\ Daniela Goya Tocchetto, Thomas Nadelhoffer \\ College of Charleston, Charleston, South Carolina, EUA \\ Silvia Helena Koller \\ Universidade Federal do Rio Grande do Sul, Porto Alegre-RS, Brasil
}

\section{RESUMO}

O objetivo deste estudo foi buscar evidências de validade e fidedignidade do Inventário do Livre-Arbítrio (ILA) para a população brasileira, além de traduzir e adaptá-lo para a língua portuguesa. Este é um instrumento dividido em duas partes. A primeira parte busca investigar força das crenças no livre-arbítrio, determinismo e dualismo. A segunda parte busca investigar relações entre esses construtos e a responsabilidade moral. Participaram deste estudo 316 participantes com idades entre 18 e 77 anos que responderam, por meio de uma plataforma on-line, a um questionário sociodemográfico e ao ILA. Tal qual na escala original, a análise fatorial exploratória revelou a existência de três fatores: livre-arbítrio, determinismo e dualismo. Os alfas de Cronbach das subescalas foram, respectivamente, 0,$81 ; 0,75 ; 0,85$. O ILA apresentou boas propriedades psicométricas para população brasileira, recomendando-se seu uso para pesquisas futuras no campo da psicologia social.

Palavras-chave: livre-arbítrio; dualismo; determinismo; escala; psicometria.

\section{ABSTRACT - Validity Evidence of the Free Will Inventory for the Brazilian Population}

The objective of this study was to search for validity and reliability evidence of the Free Will Inventory (FWI) for the Brazilian population, in addition to translating and adapting it into Portuguese. This instrument is divided into two parts. The first part seeks to investigate strength of beliefs in free will, determinism and dualism. The second part seeks to investigate relationships between these constructs and moral responsibility. A total of 316 participants between 18 and 77 years of age responded via an online platform to a socio-demographic questionnaire and the FWI. As in the original scale, the exploratory factor analysis revealed the existence of three factors: free will, determinism and dualism. Cronbach's alphas of the subscales were, respectively, $0.81 ; 0.75$; 0.85. The FWI presented good psychometric properties for the Brazilian population, and use is recommended for future research in the field of social psychology.

Keywords: free will; dualism; determinism; scale; psychometry.

\section{RESUMEN - Evidencias de Validez del Inventario de Libre Albedrío en la Población Brasileña}

El objetivo de este estudio fue buscar evidencias de validez y confiabilidad del Inventario de Libre Albedrío (ILA) en la población brasileña, y también traducirlo y adaptarlo para la lengua portuguesa. Este es un instrumento dividido en dos partes. La primera parte investiga la fuerza de creencias en el libre albedrío, determinismo y dualismo. La segunda parte investiga las relaciones entre esos constructos y la responsabilidad moral. Participaron de este estudio 316 personas con edades entre 18 y 77 años respondiendo de manera online a un cuestionario sociodemográfico y al ILA. Como en el estudio original, el análisis factorial exploratorio reveló la existencia de tres factores: libre albedrío, determinismo y dualismo. El alfa de Cronbach de las sub-escalas fueron respectivamente, 0,81; 0,75; 0,85. El ILA presentó buenas propiedades psicométricas en la población brasileña, recomendándose su uso en investigaciones futuras en el campo de la psicología social.

Palabras clave: libre albedrío; dualismo; determinismo; escala; psicometría.

O livre-arbítrio é um conceito filosófico, da metafísica, que diz respeito à liberdade de escolha da ação humana ou liberdade da vontade. Ele consiste em afirmar que há possibilidade de autodeterminação ou autocausalidade, sem quaisquer limites e condições como pré-requisito (Abbagnano, 2007). A questão do livre-arbítrio versus determinismo é debatida entre os filósofos há mais de dois mil anos. De Platão (428 a.C.-348 a.C.) 
a Bertrand Russell (1872-1970) encontram-se controvérsias e proposições acerca desse tema (Hergenhahn \& Henley, 2014). Dois eixos principais podem ser obtidos por meio da análise desse debate (Nichols, 2006): um acerca da capacidade da agência humana, e outro acerca das condições de existência de responsabilidade moral. No primeiro eixo, a discussão gira em torno de três conceitos: livre-arbítrio, determinismo e compatibilismo. O livre-arbítrio, numa definição simples, é "um tipo particular de capacidade de agentes racionais para escolher um curso de ação dentre diversas alternativas" (O'Connor, 2010). Ele é tomado como a concepção padrão, amplamente difundida e fundamento de teorias jurídicas e teológicas amplamente disseminadas.

O determinismo é "a ideia de que todo evento é necessariamente definido por eventos e condições antecedentes, juntamente com as leis da natureza" (Hoefer, 2016). O universo é fisicamente determinado e os seres humanos são parte do universo físico. Assim, todas as ações humanas são decorrentes dos eventos que as antecedem causalmente, eliminando possibilidades de resultados diferentes, se mantidas as mesmas causas. Isso implica conceber a escolha de ação humana como determinada por eventos externos aos indivíduos, de modo que sua vontade ou não entra no processo causal ou é, no máximo, um elo também determinado da cadeia causal. Ambas as concepções parecem excludentes e, segundo alguns filósofos, elas realmente são. Contudo, há alternativas e uma delas vem ganhando mais adeptos na discussão filosófica - o compatibilismo.

A ideia do compatibilismo é de que livre-arbítrio e determinismo não são excludentes (Nahmias, Morris, Nadelhoffer, \& Turner, 2006). Ela é possível ao aceitar o determinismo para o universo físico e negá-lo para os seres humanos, defendendo que a mente humana e sua relação com o cérebro são de natureza diferentes do resto do universo. O compatibilismo também resguarda, em geral, a ideia de responsabilidade moral, pois defende o livre-arbítrio, que é um dos seus requisitos, conciliando-o com o determinismo causal para o universo.

No segundo eixo, é discutida a possibilidade da existência de responsabilidade moral no caso de não haver livre-arbítrio. De um lado, há os compatibilistas, do outro, os incompatibilistas, que afirmam ser impossível haver responsabilidade moral sem livre-arbítrio. A ideia de responsabilidade moral não tem definição unívoca, todavia é tradicionalmente associada à imputação de responsabilidade dos atos de um agente sobre ele. Um agente moral não é aquele que age moralmente certo ou errado, mas alguém que pode responder plenamente por seus atos, merecendo louvor ou reprovação, prêmio ou punição (McKenna \& Coates, 2015).

Para além de questões metafísicas sobre o livre-arbítrio, atualmente se investigam as consequências funcionais de se acreditar nele. Já foi sugerido que a percepção de controle sobre o ambiente é evolutivamente adaptativa (Leotti, Iyengar, \& Ochsner, 2010). É possível que no passado, os sujeitos que acreditaram ter livre-arbítrio tenham conseguido controlar seu ambiente com maior eficácia, proporcionando um clima mais seguro para sua prole e obtendo sucesso na disseminação de seus genes (Rakos, 2004). Além disso, estudos recentes mostram que quanto menos os indivíduos creem no livre arbítrio, maior pode ser a tendência de trapacear (Vohs \& Schooler, 2008); de se comportar agressivamente (Baumeister, Masicampo, \& DeWall, 2009); e de se conformar (Alquist, Ainsworth, \& Baumeister, 2013). Em contrapartida, quanto mais os sujeitos creem no livre-arbítrio, maior a tendência de ajudar outras pessoas (Baumeister et al., 2009); maior tende a ser sua autoestima (Rakos, Laurene, Skala, \& Slane, 2008); e melhor o seu desempenho no trabalho (Stillman et al., 2010). Tal controvérsia mostra que a investigação das crenças no livre-arbítrio pode trazer contribuições para diversas áreas da Psicologia.

Para uma investigação precisa das crenças no livre-arbítrio, do ponto de vista individual, são necessários instrumentos com boas propriedades psicométricas. Diversas escalas já foram desenvolvidas com esse fim. Uma das primeiras foi a Free Will-Determinism Scale (Escala do Livre-arbítrio-Determinismo; Viney, Waldman, \& Barchilon, 1982). Ela é uma escala de autorrelato que define o livre-arbítrio como "a doutrina que assume que fazemos escolhas reais, as quais são totalmente ou parcialmente independentes de condições antecedentes" (Viney et al., 1982, p. 946). Já o determinismo é definido como a negação dessa definição, em que tudo é determinado por condições antecedentes. Essa escala coloca o livre-arbítrio e o determinismo como conceitos antagônicos. Entretanto, não é raro que as pessoas acreditem que, mesmo tudo estando determinado, haja livre-arbítrio (Nahmias et al., 2006). Assim, embora a Free Will-Determinism Scale tenha iniciado o processo de construção de escalas para investigação do livre-arbítrio, ela falha em abranger essa possibilidade de resposta, qual seja, compatibilista - uma crença concomitante no livre-arbítrio e num universo determinístico (Nadelhoffer, Shepard, Nahmias, Sripada, \& Ross, 2014). A escala é de autorrelato e composta por sete itens. Dos itens 1 a 5 , os participantes devem escolher, entre três sentenças, qual a que eles mais concordam. Nos itens 6 e 7, os participantes devem escolher entre duas sentenças com as quais eles mais concordam. A amplitude total da escala é de 7 (resposta determinista em todos os itens) a 63 (resposta pró-livre-arbítrio em todos os itens).

Outra escala desenvolvida para medir a força das crenças no livre-arbítrio foi a Free Will and Determinism Scale (Escala do Livre-arbítrio e Determinismo; Rakos et al., 2008). Embora tenha boas propriedades psicométricas, ela define o livre-arbítrio e o determinismo como polos opostos de um continuum de agência humana, apresentando a mesma fragilidade da Free Will-Determinism 
Scale de não abranger a opinião de quem crê no determinismo e no livre-arbítrio ao mesmo tempo. Ela é uma escala de autorrelato composta por 22 itens que podem ser pontuados de 1 (nunca verdadeiro) a 5 (quase sempre verdadeiro), podendo sua pontuação total variar de 22 (forte crença no determinismo) a 110 (forte crença no livre-arbitrio). Ela é dividida em duas subescalas: Arbítrio Geral (composta por 14 itens, $\alpha=0,59)$, que investiga as crenças pessoais sobre os outros terem Livre Arbítrio (e.g., uma pessoa tem livre-arbítrio independentemente de circunstâncias econômicas); e Arbítrio Pessoal (composta por oito itens, $\alpha=0,65)$, que investiga as crenças relacionadas ao livre-arbítrio pessoal (e.g., "Eu tenho livre-arbítrio mesmo quando minhas escolhas são limitadas por circunstâncias externas"). A escala apresenta boa consistência interna $(\alpha=0,72)$.

A FAD-Plus (Paulhus \& Carey, 2011) também foi desenvolvida para investigar as crenças no livre-arbítrio. Ela é de autorrelato e composta por 27 itens que variam de 1 (discordo fortemente) a 5 (concordo fortemente). Por meio de análise fatorial exploratória, os autores chegaram a quatro fatores: livre-arbítrio (composto por sete itens, $\alpha=0,70$ ), que busca investigar crenças sobre livre arbítrio (e.g., "As pessoas podem superar obstáculos caso elas queiram") e responsabilidade sobre ações individuais (e.g., "As pessoas devem assumir total responsabilidade por todas as más escolhas que fazem"); determinismo científico (composto por sete itens, $\alpha=0,69$ ), que busca investigar crenças no poder de forças biológicas (e.g., "A constituição biológica de cada um influencia seu talento e personalidade") e ambientais (e.g., "A ciência já demonstrou que o ambiente passado criou sua inteligência e personalidade atuais"); determinismo fatalístico (composto por cinco itens, $\alpha=0,82$ ), que busca investigar crenças no destino (e.g., "O destino já tem um plano para cada um de nós"); imprevisibilidade (composto por oito itens, $\alpha=0,72$ ), que busca investigar crenças no acaso (e.g. , "É difícil de prever a vida, porque tudo é quase totalmente aleatório"). Ainda que a FAD-Plus não ignore que há como crer no livre-arbítrio e no determinismo ao mesmo tempo, há um dado que coloca em dúvida a validade de construto de duas das suas subescalas: os escores da subescala de determinismo fatalístico se correlacionaram diretamente com os escores da subescala de imprevisibilidade $(r=0,19 ; p<0,05$; Paulhus \& Carey, 2011). Sob o ponto de vista teórico, é questionável que os itens estejam se referindo aos construtos aos quais aludem sendo que a imprevisibilidade é o inverso do determinismo fatalístico. Mesmo as subescalas tendo sido obtidas primariamente por meio de análises fatoriais exploratórias e tendo boas propriedades psicométricas, tais resultados tornam a validade de construto das subescalas questionáveis (Nadelhoffer et al., 2014).

Por último, na Belief in Free Will Scale (Escala de Crenças no Livre-Arbítrio; Bergner, \& Ramon, 2013), os autores definiram crença no livre-arbítrio como a aquela em que há escolha genuína, nas quais as pessoas consideram realidades alternativas e são genuinamente capazes de escolher entre elas, tendo sido sempre capazes de agir de forma diferente de como agiram. Já a crença no determinismo é definida como aquela que encara a possibilidade de autodeterminação como uma ilusão, sendo o comportamento humano o produto inevitável de forças causais, sejam elas biológicas, psicológicas, evolutivas ou ambientais (Bergner \& Ramon, 2013). A escala é composta por seis itens $(\alpha=0,73)$ que variam de 1 (discordo fortemente) a 7 (concordo fortemente). Também essa escala não é capaz de medir as crenças daqueles que creem no determinismo e no livre-arbítrio ao mesmo tempo.

Pode-se perceber que os instrumentos variam a depender de como eles conceitualizam livre-arbítrio e determinismo, sendo isso frequentemente um limitador do instrumento. A fim de superar essa questão e buscar elucidar como o livre-arbítrio se relaciona a construtos relacionados, foi proposto o Free Will Inventory (Inventário do Livre-Arbítrio (ILA); Nadelhoffer et al., 2014). O ILA é composto por 29 itens que variam de 1 (discordo fortemente) a 7 (concordo fortemente). Os itens são divididos em duas partes, as quais podem ser aplicadas juntas ou separadamente. A primeira parte do inventário é uma escala psicométrica constituída por 15 itens divididos em três subescalas: livre-arbítrio; determinismo; dualismo e não reducionismo, cada uma com cinco itens. A subescala livre-arbítrio avalia as crenças sobre a capacidade de agência humana, não o definindo como um construto antagônico ao determinismo. A subescala determinismo avalia a força das crenças na possibilidade de eventos futuros não ocorrerem diferentemente. A subescala dualismo e não reducionismo avalia a força das crenças na alma e essências humanas transcendentes (Nadelhoffer et al., 2014).

A escolha do dualismo e não reducionismo para a terceira subescala diz respeito à construção teórica do compatibilismo e de como captar as crenças nesse conceito, uma vez que ele visa acomodar a crença na verdade do determinismo causal e também no livre-arbítrio. Assim, é necessário algum conceito que faça a separação entre a vontade humana e o universo determinista causal, tais como as ideias de alma, espírito, essência, etc. As crenças nesses conceitos devem captar as ligações entre crenças no determinismo e no livre-arbítrio, mostrando-os não como excludentes, mas concomitantes.

A primeira parte do inventário busca investigar, principalmente, a força das crenças nos três construtos: livre-arbítrio, determinismo, e dualismo e não reducionismo. Entretanto, os itens não fornecem detalhes sobre o conteúdo da crença no que concerne a aspectos como a natureza do livre-arbítrio ou a relação do livre-arbítrio com a responsabilidade moral e crenças na alma. A fim de suprir essa lacuna, a segunda parte do inventário é composta por 14 itens que buscam investigar tais relações entre os três construtos (livre-arbítrio, determinismo e dualismo) e responsabilidade moral. Cada item dessa parte 
busca identificar as relações entre os construtos a partir de teorias bastante diferentes. Assim, a segunda parte não constitui uma escala psicométrica passível de ser validada tal qual a primeira parte do ILA, servindo principalmente para fornecer médias de concordância com as diversas teorias avaliadas por cada item.

Os itens do ILA foram desenvolvidos sem se referir a uma teoria específica sobre o livre-arbítrio e sem ignorar a posição de quem acredita no determinismo e no livre-arbítrio ao mesmo tempo (Nadelhoffer et al., 2014). O inventário foi construído e aplicado em uma amostra representativa de diversos grupos étnicos e de orientações religiosas díspares dos Estados Unidos. Após quatro rodadas de coletas e análises fatoriais exploratórias da primeira parte do instrumento, foi realizada uma análise fatorial confirmatória com três fatores que chegou à versão final do inventário. A primeira parte do inventário possui boas propriedades psicométricas. $\mathrm{O}$ alfa de Cronbach da subescala de livre-arbítrio foi 0,803 , da subescala de determinismo 0,772 e a da subescala de dualismo 0,771. A segunda parte do inventário foi capaz de fornecer indicativos do conteúdo das crenças dos participantes, como a possibilidade de existência de determinismo e livre-arbítrio ao mesmo tempo (Nadelhoffer et al., 2014).

Embora não haja estudos de replicação da estrutura fatorial proposta (Nadelhoffer et al., 2014), o ILA já foi utilizado em pesquisas sobre diferentes temas. Ele já foi utilizado como medida do livre-arbítrio em um estudo que buscou investigar a relação entre crenças sobre livre-arbítrio e sentimentos de paixão (Boudesseul, Lantian, Cova, \& Bègue, 2016). Os indivíduos que mais creem no livre-arbítrio relataram sentir maiores níveis de paixão em seus relacionamentos. O inventário também foi utilizado em um estudo que investigou como as crenças sobre o livre-arbítrio influenciam o grau de importância que os indivíduos conferem a decisões tomadas por eles em eventos importantes de sua história pessoal e que poderiam ter sido diferentes (Seto, Hicks, Davis, \& Smallman, 2014). Quando os indivíduos refletiam sobre o passado, quanto mais acreditavam no livre arbítrio, mais tendiam a conferir importância às decisões que tomaram em situações importantes. Além de uma medida de livre-arbítrio, o ILA já foi utilizado como medida de crenças no dualismo, definido como a crença em uma alma com existência separada do corpo físico (Shepard \& May, 2014). Os indivíduos que mostravam dualismo consideraram que sua identidade seria alterada caso eles tivessem que colocar um chip no cérebro (e.g., "De certa forma, o chip transformaria a pessoa em uma espécie de cyborg"). Portanto, quanto mais dualista, mais os participantes tendiam a acreditar que um procedimento como esse pudesse mudar suas identidades. Em todos esses experimentos, o ILA se mostrou uma medida adequada, prática e versátil, porque permite a investigação de diferentes temas. Portanto, por ter boas propriedades psicométricas, não apresentar resultados que fragilizam sua validade de construto e ter se mostrado uma medida versátil e eficaz, o presente estudo teve como objetivo adaptar para a língua portuguesa o ILA e analisar suas propriedades psicométricas no contexto brasileiro, sendo o primeiro estudo que se propõe a replicar sua estrutura fatorial original.

\section{Método}

\section{Participantes}

Participaram deste estudo 321 indivíduos com idades entre 14 e 77 anos. Destes, cinco foram removidos por terem menos de 18 anos. Assim, os dados são de 316 indivíduos com idades entre 18 e 77 anos $(M=32,31$; $D P=12,32)$, mediana $=28$. Mais da metade da amostra foi composta por mulheres $(55,7 \%)$. Os dados demográficos dos participantes encontram-se na Tabela 1.

Tabela 1

Dados Sociodemográficos da Amostra

\begin{tabular}{lc}
\hline & Grupo \\
\hline Etnia & $\mathrm{n}(\%)$ \\
Branca & $264(83,5)$ \\
Parda & $34(10,8)$ \\
Preta & $6(1,9)$ \\
Amarela & $3(0,9)$ \\
Indígena & $1(0,3)$ \\
Outra & $8(2,5)$ \\
Tem alguma religião ou crença espiritual & $189(60,6)$ \\
Sim & $123(39,4)$ \\
Não & \\
Religião ou crença espiritual & $74(39,4)$ \\
Não tem religião, mas crê em Deus ou algo superior & $51(27,1)$
\end{tabular}


Tabela 1 (continuação)

Dados Sociodemográficos da Amostra

\begin{tabular}{lcc}
\hline & Grupo & $\mathrm{n}(\%)$ \\
\hline Espírita & $39(20,7)$ \\
Umbanda & $8(4,3)$ \\
Evangélica & $7(3,7)$ \\
Protestante & $5(2,7)$ \\
Judaica & $2(1,1)$ \\
Candomblé & $1(0,5)$ \\
Islâmica & $1(0,5)$ \\
Renda domiciliar mensal & $43(13,6)$ \\
Maior ou igual a 20 salários mínimos & $93(29,4)$ \\
De 10 a 20 salários mínimos & $110(34,8)$ \\
De 4 a 10 salários mínimos & $51(16,1)$ \\
De 2 a 4 salários mínimos & $13(4,1)$ \\
Até 2 salários mínimos & $6(1,9)$ \\
Não sabe & \\
\hline
\end{tabular}

\section{Instrumento}

O estudo começou pela tradução do instrumento original. O ILA foi traduzido para o português por dois pesquisadores fluentes em língua inglesa. Em seguida, os itens foram analisados por dois experts na área da avaliação psicológica, a fim de avaliar suas traduções. Posteriormente, foi feita a retrotradução para o inglês, a qual foi avaliada por um pesquisador bilíngue. Em todas as etapas foram levados em conta os aspectos relevantes para a validação de instrumentos psicológicos entre culturas (Borsa, Damásio, \& Bandeira, 2012), tais como equivalência conceitual e idiomática.

\section{Procedimento}

Inicialmente o projeto foi submetido e aprovado pelo Comitê de Ética e Pesquisa da universidade a que se encontra vinculado. Em seguida, a coleta de dados foi realizada por meio de formulário produzido no site Survey Monkey, de forma a apresentar os itens separadamente (um por tela) e aleatoriamente a cada acesso, a fim de evitar efeitos de ordem. Os participantes foram convidados a participar por meio de um link de divulgação postado em rede social (Facebook), entre 2014 e 2016. Antes de responder às perguntas do questionário, os indivíduos expressaram sua concordância por meio de Termo de Consentimento Livre e Esclarecido. O anonimato foi garantido e somente os pesquisadores tiveram acesso aos dados, conforme considerações éticas da Resolução $n^{\circ}$. 510/2016 do Conselho Nacional de Saúde para pesquisas com seres humanos. A amostra foi recolhida por conveniência. Primeiramente foi aplicado o questionário sociodemográfico, em seguida a parte 1 e depois a parte 2 do ILA. Os itens originais da primeira parte do ILA e suas respectivas traduções se encontram na Tabela 2.

\section{Análise de Dados}

A versão brasileira do ILA foi submetida a uma análise fatorial exploratória (AFE) para investigação de sua estrutura fatorial no contexto nacional. Dois métodos avaliativos foram utilizados para observar a adequação da matriz de dados à fatoração: o critério de Kaiser-Meyer-Olkin (KMO) e o teste de esfericidade de Bartlett. Em seguida, a AFE foi conduzida a partir do método de extração de fatoração por eixos principais, com rotação oblimin direta. Embora recomende-se valores de saturação nos fatores iguais ou superiores a 0,3 (Pasquali, 2001), estabeleceu-se o valor de saturação 0,4 pois assim pode-se distinguir com maior precisão os itens constituintes de cada fator.

Posteriormente foram realizadas análises fatoriais confirmatórias a fim de avaliar qual modelo se ajustava melhor aos dados. Foi escolhido analisar a estrutura fatorial resultante da análise fatorial exploratória e a estrutura trifatorial proposta no estudo original. O método de estimação utilizado foi o Weighted Least Squares Mean and Variance adjusted (WLSMV; Quadrados Mínimos Ponderados Robustos) e as medidas de ajustamento foram o CFI (Comparative Fit Index; índice de Ajuste Comparativo), o TLI (Tucker-Lewis Index; Índice de Tucker-Lewis) e o RMSEA (Root Mean Square Error of Approximation; raiz do erro quadrático médio de aproximação). Os critérios adotados para adequação dos índices de ajuste de modelo foram CFI e TLI $>0,9$ e RMSEA <0,08 (Holgado-Tello, Chacón-Moscoso, Barbero-García, \& Vila-Abad, 2010). Estas análises foram feitas por meio do software Mplus versão 7.

Para investigação de consistência interna, foram calculados alfas de Cronbach do escore geral do ILA e de suas subescalas. Em seguida foram feitos testes $t$ de Student a fim de comparar as médias nas subescalas por meio das variáveis sociodemográficas: etnia, gênero, renda domiciliar mensal e religiosidade. Depois foram feitas correlações entre os escores das subescalas. Por fim, foram calculadas as médias e desvios padrão dos escores da parte 2 do ILA. 
Tabela 2

Versão Original e Traduzida dos Itens da Primeira Parte do ILA

\begin{tabular}{cll}
\hline Item & \multicolumn{1}{c}{ Versão traduzida } & Versão original (Nadelhoffer et al., 2014) \\
\hline 1 & As pessoas sempre podem agir de outro modo. & People always have the ability to do otherwise. \\
2 & $\begin{array}{l}\text { Tudo o que já aconteceu teve que acontecer } \\
\text { precisamente como aconteceu, levando em } \\
\text { consideração o que ocorreu anteriormente. }\end{array}$ & $\begin{array}{l}\text { Everything that has ever happened had to happen } \\
\text { precisely as it did, given what happened before. }\end{array}$
\end{tabular}

3 O fato de termos uma alma independente do corpo físico é o que faz dos humanos seres singulares.

4 As pessoas sempre têm livre-arbítrio.

5 Todos os eventos que já aconteceram, incluindo as decisões e ações humanas, foram totalmente determinados por eventos anteriores.

6 A ação humana só pode ser compreendida em relação a nossa alma e nossa mente, não somente em termos de cérebro.

7 O modo como a vida das pessoas se desdobra é completamente dependente da escolha delas.

8 As escolhas e ações das pessoas devem ocorrer precisamente do modo como ocorrem por causa das leis da natureza e do modo como as coisas foram no passado distante.

9 Cada pessoa tem uma essência não física que a torna única.

10 As pessoas têm, essencialmente, controle total sobre suas decisões e ações.

11 Um supercomputador que pudesse saber tudo sobre o modo como o universo está agora poderia saber tudo sobre o modo como o universo estará no futuro.

12 A mente humana não pode simplesmente ser reduzida ao cérebro.

13 As pessoas têm livre-arbítrio mesmo quando suas escolhas são completamente limitadas por circunstâncias externas.

14 Dado o modo como as coisas ocorreram no Big Bang, há somente um modo de tudo acontecer no universo depois disso.

15 A mente humana é mais do que simplesmente uma máquina biológica complicada.
The fact that we have souls that are distinct from our material bodies is what makes humans unique.

People always have free will.

Every event that has ever occurred, including human decisions and actions, was completely determined by prior events.

Human action can only be understood in terms of our souls and minds and not just in terms of our brains.

How people's lives unfold is completely up to them.

People's choices and actions must happen precisely the way they do because of the laws of nature and the way things were in the distant past.

Each person has a non-physical essence that makes that person unique.

People ultimately have complete control over their decisions and their actions.

A supercomputer that could know everything about the way the universe is now could know everything about the way the universe will be in the future.

The human mind cannot simply be reduced to the brain.

People have free will even when their choices are completely limited by external circumstances.

Given the way things were at the Big Bang, there is only one way for everything to happen in the universe after that.

The human mind is more than just a complicated biological machine.

\section{Resultados}

\section{Análise Fatorial Exploratória}

A análise fatorial exploratória resultou em três fatores que explicam 57,78\% da variância das respostas: $27,62 \%$ da variância explicada pelo fator dualismo e não reducionismo, $17,36 \%$ explicada pelo fator determinismo e $12,81 \%$ explicado pelo fator livre-arbítrio. Essa solução correspondeu aos requisitos exigidos para a realização da análise fatorial (Hair, Anderson, Tatham, \& Black, 2005), com medida de Kaiser-Meyer-Olkin (KMO) 0,82 e teste de esfericidade de Bartlett significativo $\left(\chi^{2}=1648,36\right.$; $p<0,001$ ). O Scree Plot (Figura 1) também apresenta três fatores diferenciáveis.

As saturações de cada item nos respectivos fatores são apresentadas na Tabela 3. Todos os itens carregaram em apenas um fator referente a cada subescala $(M=0,75)$. Assim, a distribuição dos itens pelos fatores na versão em português do ILA é bastante semelhante à da versão original, podendo os fatores serem descritos da mesma forma. 


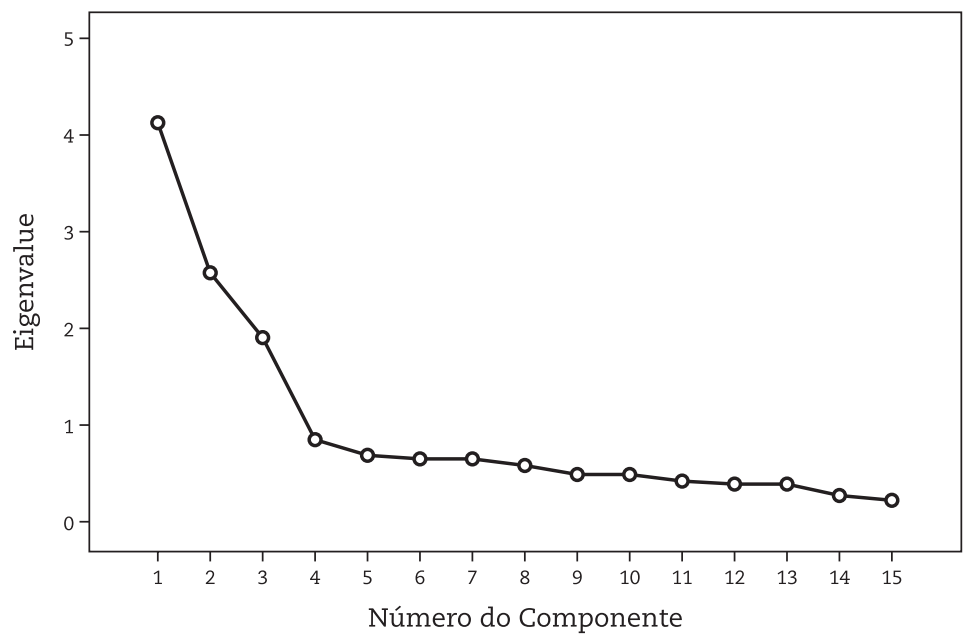

Figura 1. Scree Plot dos fatores

Tabela 3

Matriz Rotada com as Cargas Fatoriais do ILA

\begin{tabular}{|c|c|c|c|}
\hline \multirow{2}{*}{ Conteúdo } & \multicolumn{3}{|c|}{ Fator } \\
\hline & 1 & 2 & 3 \\
\hline Cada pessoa tem uma essência não física que a torna única. & 0,826 & 0,051 & $-0,028$ \\
\hline A mente humana é mais do que simplesmente uma máquina biológica complicada. & 0,794 & $-0,139$ & $-0,010$ \\
\hline A mente humana não pode simplesmente ser reduzida ao cérebro. & 0,692 & $-0,053$ & $-0,065$ \\
\hline $\begin{array}{l}\text { A ação humana só pode ser compreendida em relação a nossa alma e } \\
\text { nossa mente, não somente em termos de cérebro. }\end{array}$ & 0,660 & 0,040 & 0,096 \\
\hline $\begin{array}{l}\text { O fato de termos uma alma independente do corpo físico é o que faz } \\
\text { dos humanos seres singulares. }\end{array}$ & 0,639 & 0,146 & 0,122 \\
\hline $\begin{array}{l}\text { As escolhas e ações das pessoas devem ocorrer precisamente do modo como } \\
\text { ocorrem por causa das leis da natureza e do modo como as coisas foram no } \\
\text { passado distante. }\end{array}$ & 0,114 & 0,754 & $-0,096$ \\
\hline $\begin{array}{l}\text { Tudo o que já aconteceu teve que acontecer precisamente como } \\
\text { aconteceu, levando em consideração o que ocorreu anteriormente. }\end{array}$ & 0,099 & 0,661 & 0,032 \\
\hline $\begin{array}{l}\text { Todos os eventos que já aconteceram, incluindo as decisões e ações } \\
\text { humanas, foram totalmente determinados por eventos anteriores. }\end{array}$ & 0,002 & 0,658 & 0,075 \\
\hline $\begin{array}{l}\text { Dado o modo como as coisas ocorreram no Big Bang, há somente } \\
\text { um modo de tudo acontecer no universo depois disso. }\end{array}$ & $-0,051$ & 0,544 & 0,006 \\
\hline $\begin{array}{l}\text { Um supercomputador que pudesse saber tudo sobre o modo como o universo } \\
\text { está agora poderia saber tudo sobre o modo como o universo estará no futuro. }\end{array}$ & $-0,113$ & 0,464 & $-0,048$ \\
\hline As pessoas sempre têm livre-arbítrio. & $-0,080$ & $-0,074$ & 0,885 \\
\hline As pessoas têm, essencialmente, controle total sobre suas decisões e ações. & $-0,070$ & 0,047 & 0,730 \\
\hline $\begin{array}{l}\text { As pessoas têm livre-arbítrio mesmo quando suas escolhas são } \\
\text { completamente limitadas por circunstâncias externas. }\end{array}$ & 0,030 & $-0,074$ & 0,662 \\
\hline $\begin{array}{l}\text { O modo como a vida das pessoas se desdobra é } \\
\text { completamente dependente da escolha delas }\end{array}$ & 0,057 & 0,134 & 0,553 \\
\hline As pessoas sempre podem agir de outro modo. & 0,164 & $-0,092$ & 0,517 \\
\hline
\end{tabular}

Nota. Método de extração: Fatoração pelo eixo principal; método de rotação: oblimin direto 
O alfa de Cronbach foi calculado para determinar a consistência interna do ILA e de suas subescalas. Os resultados indicaram que o ILA possui alta consistência interna geral $(\alpha=0,78)$, bem como as subescalas livre-arbítrio $(\alpha=0,81)$, determinismo $(\alpha=0,75)$ e dualismo e não reducionismo $(\alpha=0,85)$.

\section{Análise Fatorial Confirmatória}

Como a estrutura fatorial resultante da análise fatorial exploratória foi trifatorial e cada fator sendo composto pelos mesmos itens do estudo original, optou-se por analisar os índices de ajuste de modelo apenas dessa estrutura. Como não houve correlação estatisticamente significativa entre o fator determinismo e os outros fatores, tanto no atual estudo como no estudo original (como descrito na seção posterior deste estudo), foi feita análise fatorial confirmatória considerando os fatores livre-arbítrio e dualismo como ortogonais em relação ao fator determinismo. Os índices de ajuste foram então considerados satisfatórios: $\chi^{2}=227,906$; graus de liberdade $(g l)=89 ; \chi^{2} / g l=2,56$; CFI: 0,960; TLI: 0,953; RMSEA: 0,070 IC $90 \%[0,059 ; 0,082]$.

\section{Análises Descritivas e Inferenciais}

Foi realizada uma análise descritiva dos 15 itens da primeira parte do instrumento. As análises consideraram as variáveis sociodemográficas: etnia, gênero, classe socioeconômica e religiosidade.

Os participantes obtiveram média de 22,55 na subescala livre-arbítrio $(D P=6,69), 15,32(D P=5,95)$ na determinismo e 23,32 $(D P=7,52)$ na dualismo, todas com amplitude de 5 a 35 . Um teste $t$ de Student indicou diferença significativa entre as médias por gênero na subescala livre-arbítrio $\Delta(2,8)$ IC 95\% [1,34; 4,26], $t(314)=3,78, p<0,001, d$ de Cohen $=0,43$, com as mulheres $(M=23,79 ; D P=6,66)$ apresentando média mais alta do que os homens $(M=20,99 ; D P=6,42)$.
A diferença de médias por gênero também foi encontrada na subescala dualismo, $\Delta(4,24)$ IC $95 \%[2,62$; $5,85], t(314)=5,17, p<0,001, d=0,58 \mathrm{com}$ as mulheres $(M=25,20 ; D P=6,94)$ apresentando média mais alta do que os homens $(M=20,96 ; D P=7,58)$.

Também foram realizados testes $t$ de Student a fim de verificar se houve diferença significativa de médias nas subescalas entre os que têm algum tipo de religiosidade ou crença espiritual e os que não têm. Essa diferença foi encontrada na subescala livre-arbítrio $\Delta(3,74)$ IC $95 \%$ $[2,28 ; 5,21], t(310)=5,02, p<0,001, d=0,57$ com pessoas com religiosidade ou crença espiritual apresentando média maior $(M=24,08 ; D P=6,25)$ do que aqueles que não têm $(M=20,34 ; D P=6,71)$. Tal diferença significativa também foi encontrada na subescala dualismo $\Delta(9,04)$ IC $95 \%[7,65 ; 10,43], t(310)=12,81, p<0,001, d=1,46$ tendo as pessoas que expressaram ter alguma religiosidade ou crença espiritual apresentado média maior $(M=26,93$; $D P=5,29)$ do que as que não têm $(M=17,89 ; \mathrm{DP}=7,15)$.

A fim de investigar se houve diferença significativa nos escores das subescalas entre os adeptos das diferentes religiões, foi realizada uma ANOVA unidirecional. Foi encontrada diferença significativa para os escores da subescala dualismo, $F(8,179)=2,153, p<0,05, \eta^{2}=0,088$. Entretanto, testes post hoc não eram possíveis em função de haver apenas um adepto do candomblé e um islâmico na amostra. Esses casos foram excluídos para que testes post hoc fossem possíveis. Após nova realização da ANOVA com os casos excluídos, a diferença significativa deixou de existir $F(6,179)=1,98, p=0,07, \eta^{2}=0,062$. Entre as subescalas do ILA, os escores do livre-arbítrio e dualismo foram os únicos que se correlacionaram $r(2)=0,37, p<0,001$.

A segunda parte do inventário busca fornecer mais dados para melhor compreensão de como diferentes construtos se relacionam. As médias e desvios padrão dos escores na parte 2 do ILA podem ser conferidos na Tabela 4 .

Tabela 4

Médias e Desvios Padrão dos Itens da Parte 2 do ILA

\begin{tabular}{cccc}
\hline Item & Conteúdo & Média (DP) \\
\hline 1 & $\begin{array}{l}\text { O livre arbítrio é a capacidade de fazer escolhas diferentes mesmos e tudo o que orienta a } \\
\text { escolha de alguém (ex.: o passado, a situação e os desejos, crenças, etc.) fosse exatamente igual. }\end{array}$ & 5,36 (1,42)
\end{tabular}

2 Para sermos responsáveis por nossas decisões e ações, devemos também ser responsáveis por todas as nossas decisões e ações anteriores que resultaram no presente momento.

3 O livre-arbítrio é a capacidade de fazer uma escolha com base nas crenças e desejos de uma pessoa de modo que, se a pessoa tivesse diferentes crenças e desejos, a escolha dessa pessoa também teria sido diferente.

4 As pessoas merecem ser culpadas e punidas por más ações somente se tiverem agido com seu próprio livre-arbítrio.

5 As pessoas poderiam ter livre-arbítrio mesmo se os cientistas descobrissem todas as leis que governam todo o comportamento humano. 
Tabela 4 (continuação)

Médias e Desuios Padrão dos Itens da Parte 2 do ILA

\begin{tabular}{|c|c|c|}
\hline Item & Conteúdo & Média (DP) \\
\hline 6 & $\begin{array}{l}\text { As pessoas que prejudicam outras merecem ser punidas mesmo se a punição não produzir } \\
\text { nenhum benefício positivo ao malfeitor ou à sociedade - ex.:, reabilitação, dissuadir outros } \\
\text { malfeitores em potencial, etc. }\end{array}$ & $3,62(1,87)$ \\
\hline 7 & $\begin{array}{l}\text { Ter livre-arbítrio significa que as decisões e ações de uma pessoa não poderiam ser perfeitamente } \\
\text { previstas por outra pessoa, não importa quantas informações estivessem disponíveis. }\end{array}$ & $4,76(1,73)$ \\
\hline 8 & $\begin{array}{l}\text { Se as pessoas não tivessem a alma independente do corpo físico (ou imaterial), } \\
\text { então elas não teriam responsabilidade moral. }\end{array}$ & $2,74(1,62)$ \\
\hline 9 & $\begin{array}{l}\text { Ter livre-arbítrio é ser capaz de fazer coisas acontecerem no mundo } \\
\text { sem ao mesmo tempo ser levado a fazer essas coisas acontecerem. }\end{array}$ & $4,42(1,65)$ \\
\hline 10 & $\begin{array}{l}\text { As pessoas que agem de maneira nociva devem ser reabilitadas } \\
\text { de modo a não mais representarem uma ameaça à sociedade. }\end{array}$ & $5,54(1,28)$ \\
\hline 11 & $\begin{array}{l}\text { Se as pessoas não tivessem a alma independente do corpo físico (ou imaterial), } \\
\text { então elas não teriam livre-arbítrio. }\end{array}$ & $3,04(1,79)$ \\
\hline 12 & $\begin{array}{l}\text { As pessoas que agem de maneira nociva devem ser punidas de modo que outros } \\
\text { malfeitores em potencial sejam dissuadidos de realizar ações nocivas semelhantes. }\end{array}$ & $4,65(1,78)$ \\
\hline 13 & $\begin{array}{l}\text { As pessoas têm livre-arbítrio à medida que são capazes de fazer } \\
\text { o que querem sem serem coagidas ou forçadas por outras. }\end{array}$ & $4,99(1,55)$ \\
\hline 14 & $\begin{array}{l}\text { As pessoas poderiam ser moralmente responsáveis mesmo se os cientistas } \\
\text { descobrissem todas as leis que governam o comportamento humano. }\end{array}$ & $5,35(1,44)$ \\
\hline
\end{tabular}

Nota. $n=282$. Itens ímpares $(1,3,5,7,9,11$ e 13) medem crenças acerca da natureza do livre-arbítrio. Itens pares (2, 4, 6, 8, 10, 12 e 14) acerca da responsabilidade moral

\section{Discussão}

O presente estudo traduziu e validou para o português brasileiro o inventário ILA que permite avaliar as crenças pessoais no livre-arbítrio, determinismo e dualismo e não reducionismo. A estrutura fatorial original composta por três subescalas manteve-se na versão adaptada, explicando $57,78 \%$ da variância com bons valores de consistência interna. Ademais, a análise fatorial confirmatória apresentou bons índices de ajuste desse modelo, os quais foram bastante similares aos do estudo original (Nadelhoffer et al., 2014). Portanto, o ILA é uma medida eficaz para avaliar livre-arbítrio, determinismo e dualismo no contexto brasileiro, segundo os resultados obtidos com essa amostra.

Os fatores livre-arbítrio e determinismo carregaram separadamente e não se correlacionaram, conforme outros estudos que utilizaram tanto o ILA (Boudesseul et al., 2016) quanto outros instrumentos (Paulhus \& Carey, 2011). Isso dá suporte à corrente teórica que afirma que o livre-arbítrio e o determinismo podem existir separadamente sem necessariamente estarem correlacionados (Nichols, 2006). Tal teoria é respaldada ainda pelos índices de ajuste resultantes das análises fatoriais confirmatórias, os quais foram satisfatórios considerando os fatores livre arbítrio e dualismo como ortogonais em relação ao fator determinismo.
Foram encontradas diferenças significativas entre os escores nas subescalas de livre-arbítrio e dualismo com relação ao gênero dos participantes, sendo que as mulheres apresentaram médias mais altas em ambas as subescalas. No estudo original (Nadelhoffer et al., 2014), somente a relação com a subescala de dualismo foi encontrada, com as mulheres apresentando pontuação maiores entre participantes caucasianos. Essa é uma diferença cultural que poderá ser mais investigada em estudos futuros.

Também foi encontrada diferença estatisticamente significativa entre ter religiosidade ou crença espiritual e escores nas subescalas de livre-arbítrio e dualismo, o que não foi investigado até então em estudos que utilizaram o ILA. Os participantes que informaram ter algum grau de religiosidade ou crença espiritual obtiveram escores maiores tanto na subescala livre-arbítrio, quanto na de dualismo. A maior pontuação na subescala dualismo é explicável na medida em que mais da metade da amostra tem algum tipo de crença espiritual ou é adepta de religiões que, na sua doutrina, discernem corpo e alma, como é o caso do espiritismo, do catolicismo e do protestantismo. Logo, aqueles que não possuem uma crença espiritual ou religiosa possivelmente tendem a ser mais materialistas, isto é, crer que os seres humanos são apenas físicos, sem uma essência imaterial.

Já os maiores escores na subescala livre-arbítrio por parte das pessoas com alguma religião ou crença 
espiritual é um dado que poderá ser melhor investigado. Uma vez que não houve diferença significativa nos escores de determinismo entre esses dois grupos, não é possível atribuir a diferença na pontuação do livre-arbítrio a crenças no determinismo, advindas do materialismo, por parte dos que não possuem religiosidade ou crença espiritual. Ou seja, o grupo com crenças religiosas ou espirituais pontuou mais alto na subescala livre-arbítrio, de forma coerente do ponto de vista conceitual, mas o grupo que não possui essas crenças não pontuou mais alto na subescala do livre-arbítrio, o que seria uma expectativa coerente conceitualmente.

Foi encontrada correlação significativa entre o item 8 da parte 2 do ILA (i.e., "Se as pessoas não tivessem a alma independente do corpo físico (ou imaterial), então elas não teriam responsabilidade moral") e os escores na subescala dualismo, $r(3)=0,39, p<0,001$. O resultado pode indicar que quanto mais as pessoas tendem a crer no dualismo, mais elas tendem a encarar a alma como o que faz com que sejam moralmente responsáveis por suas ações.

Uma limitação do presente estudo foi a diferença do número de respondentes da parte 1 em relação à parte 2. Possivelmente por ele ter sido aplicado pela internet, uma parcela dos participantes não respondeu ao questionário até o fim, provocando redução no número de pessoas que chegaram a responder à parte 2 do ILA. Outra limitação é que parte expressiva da amostra se declarou de etnia branca, o que não corresponde à diversidade étnica da sociedade brasileira (IBGE, 2008).
Assim, estudos futuros devem investigar as propriedades do instrumento com amostras mais representativas do perfil étnico nacional. Além disso, poucas pessoas de baixa renda estiveram presentes na amostra. Outro aspecto relevante a considerar foi o grau de compreensão do instrumento. Breve análise qualitativa de comentários deixados pelos participantes na última seção do estudo revela que o instrumento requer boas habilidades de compreensão (e.g., "Algumas questões são difíceis de compreender", "Para responder algumas perguntas tem de se pensar muito"), sendo provavelmente mais adequado para amostras de pessoas com, no mínimo, ensino médio completo. Isso pode limitar sua aplicabilidade, posto que, segundo dados da OECD (2015), apenas 33\% da população brasileira entre 25 e 64 anos tem o ensino médio completo. Todas essas limitações da amostra sugerem que é necessário investigar melhor as crenças de populações mais diversas do ponto de vista racial, socioeconômico e educacional.

Por fim, a medida é válida e confiável para o contexto brasileiro. $\mathrm{O}$ atual estudo encontrou uma estrutura trifatorial com boa consistência interna. Além disso, diferenças significativas entre os escores puderam ser encontradas com relação às variáveis socioeconômicas, gênero e ter religião ou crença espiritual, podendo pesquisas futuras investigarem mais a fundo tais relações. Os resultados indicam, ainda, que a versão brasileira é adequada e permite utilização em diversos contextos que busquem investigar e ampliar o conhecimento sobre os construtos livre-arbítrio, determinismo e dualismo.

\section{Referências}

Abbagnano, Nicola. (2007). Dicionário de filosofia. São Paulo: Martins Fontes.

Alquist, J. L., Ainsworth, S. E., \& Baumeister, R. F. (2013). Determined to conform: Disbelief in free will increases conformity. Journal of Experimental Social Psychology, 49(1), 80-86. doi: 10.1016/j.jesp.2012.08.015

Baumeister, R. F., Masicampo, E. J., \& DeWall, N. (2009). Prosocial benefits of feeling free: Disbelief in free will increases aggression and reduces helpfulness. Personality and Social Psychology Bulletin, 35(2), 260-268. doi: 10.1177/0146167208327217

Bergner, R. M., \& Ramon, A. (2013). Some implications of beliefs in altruism, free will, and nonreductionism. The Journal of Social Psychology, 153(5), 598-618. doi: 10.1080/00224545.2013.798249

Borsa, J. C., Damásio, B. F., \& Bandeira, D. R. (2012). Adaptação e validação de instrumentos psicológicos entre culturas: algumas considerações. Paidéia, 22(53), 423-432. doi: 10.1590/1982-43272253201314

Boudesseul, J., Lantian, A., Cova, F., \& Bègue, L. (2016). Free Love? On the relation between belief in free will, determinism, and passionate love. Consciousness and Cognition, 46, 47-59. doi: 10.1016/j.concog.2016.09.003

Hair, J. F., Anderson, R. E., Tatham, R. L., \& Black, W. C. (2005). Análise multivariada de dados. Porto Alegre: Bookman.

Hergenhahn, B.R., \& Henley, T.B. (7 ed.) (2014). An introduction to the history of psychology. California: Cengage Learning.

Hoefer, C. (2016). Causal determinism. The Stanford Encyclopedia of Philosophy, Edward N. Zalta (ed.). Recuperado de https://plato.stanford. edu/archives/spr2016/entries/determinism-causal/

Holgado-Tello, F. P., Chacón-Moscoso, S., Barbero-García, I., \& Vila-Abad, E. (2010). Polychoric versus Pearson correlations in exploratory and confirmatory factor analysis of ordinal variables. Quality \& Quantity, 44(1), 153-166. doi: 10.1007/s11135-008-9190-y

IBGE (2008). Características étnico-raciais da população: um estudo das categorias de classificação de cor ou raça. Rio de Janeiro: IBGE.

Leotti, L. A., Iyengar, S. S., \& Ochsner, K. N. (2011). Born to choose: The origins and value of the need for control. Trends in Cognitive Science, 14(10), 457-463. doi: 10.1016/j.tics.2010.08.001

McKenna, M., \& Coates, D. J. (2015) Compatibilism. The Stanford Encyclopedia of Philosophy, Edward N. Zalta (Ed.). Recuperado de https:// plato.stanford.edu/archives/win2016/entries/compatibilism/

Nadelhoffer, T., Shepard, J., Nahmias, E., Sripada, C., \& Ross, L.T. (2014). The free will inventory: Measuring beliefs about agency and responsibility. Consciousness and Cognition, 25, 27-41. doi: 10.1016/j.concog.2014.01.006 
Nahmias, E., Morris, S.G., Nadelhoffer, T., \& Turner, J. (2006). Is incompatibilism intuitive? Philosophy and Phenomenological Research, 73(1), 28-53. doi: 10.1111/j.1933-1592.2006.tb00603.x

Nichols, S. (2006). Folk intuitions on free will. Journal of Cognition and Culture, 6(1), 57-86. doi: 10.1163/156853706776931385

O'Connor, T. (2010). Free Will. The Stanford Encyclopedia of Philosophy, Edward N. Zalta (ed.). Recuperado de https://plato.stanford.edu/ archives/sum2016/entries/freewill/

OECD. Organisation for Economic Co-operation and Development. (2015). Brasil Country Note. Education at a Glance 2015: OECD Indicators. Recuperado de https://www.oecd.org/brazil/Education-at-a-glance-2015-Brazil-in-Portuguese.pdf

Pasquali, L. (2001). Testes referentes a construto: teoria e modelo de construção. Em L. Pasquali (Ed.) Instrumentos psicológicos: manual prático de elaboração. (pp. 37-71). Brasília: LabPAM/IBAP.

Paulhus, D. L., \& Carey, J. M. (2011). The FAD-Plus: Measuring lay beliefs regarding free will and related constructs. Journal of Personality Assessment, 93(1), 96-104. doi: 10.1080/00223891.2010.528483

Rakos, R. F. (2004). The belief in free will as a biological adaptation: Thinking inside and outside the behavior analytic box. European Journal of Behavior Analysis, 5(2), 95-103. doi: 10.1080/15021149.2004.11434235

Rakos, R. F., Laurene, K. R., Skala, S., \& Slane, S. (2008). Belief in free will: Measurement and conceptualization innovations. Behavior and Social Issues, 17(1), 20-39. doi: 10.5210/bsi.v17i1.1929

Seto, E., Hicks, J.A., Davis, W.E., \& Smallman, R. (2014). Free will, counterfactual reflection, and the meaningfulness of life events. Social Psychological and Personality Science, 6(3), 243-250. doi: 10.1177/1948550614559603

Shepard, J., \& May, J. (2014). Does belief in dualism protect against maladptive psychosocial responses to deep brain stimulation? an empirical exploration. AJOB Neuroscience, 5(4), 40-64. doi: 10.1080/21507740.2014.951778

Stillman, T. F., Baumeister, R. F., Vohs, K. D., Lambert, N. M., Fincham, F. D., \& Brewer, L. E. (2010). Personal philosophy and personnel achievement: Belief in free will predicts better job performance. Social Psychological and Personality Science, 1(1), 43-50. doi: $10.1177 / 1948550609351600$

Viney, W., Waldman, D. A., \& Barchilon, J. (1982). Attitudes toward punishment in relation to beliefs in free will and determinism. Human Relations, 35(11), 939-950. doi: 10.1177/001872678203501101

Vohs, K. D., \& Schooler, J. W. (2008). The value of believing in free will. Psychological Science, 19(1), 49-54. doi: 10.1111/j.1467-9280.2008.02045.x

\section{Sobre os autores}

Thiago Rafael Santin é Mestre em filosofia pela Pontifícia Universidade Católica do Rio Grande do Sul (PUCRS), graduando em psicologia na Universidade Federal do Rio Grande do Sul (UFRGS), Porto Alegre, RS, Brasil.

Felipe Vilanova é graduando em psicologia na Universidade Federal do Rio Grande do Sul (UFRGS), Porto Alegre, RS, Brasil.

Ângelo Brandelli Costa é Doutor em psicologia pela Universidade Federal do Rio Grande do Sul (UFRGS), professor adjunto na Pontifícia Universidade Católica do Rio Grande do Sul (PUCRS), Porto Alegre, RS, Brasil.

Daniela Goya Tocchetto é Doutora em filosofia pela Universidade Federal do Rio Grande do Sul (UFRGS), professora adjunta no College of Charleston - Charleston, South Carolina, EUA.

Thomas Nadelhoffer é Doutor em filosofia pela Florida State University, professor assistente no College of Charleston - Charleston, South Carolina, EUA.

Silvia Helena Koller é Doutora em educação pela Pontifícia Universidade Católica do Rio Grande do Sul (PUCRS), professora titular na Universidade Federal do Rio Grande do Sul (UFRGS), Porto Alegre, RS, Brasil. 